\title{
Retour sur « Hommage à André Leroi-Gourhan »
}

Jean-François Quilici-Pacaud

\section{OpenEdition}

\section{Journals}

Édition électronique

URL : https://journals.openedition.org/tc/5044

DOI : $10.4000 /$ tc. 5044

ISSN : 1952-420X

\section{Éditeur}

Éditions de l'EHESS

\section{Édition imprimée}

Date de publication : 30 juin 2010

Pagination : 68-83

ISSN : 0248-6016

\section{Référence électronique}

Jean-François Quilici-Pacaud, « Retour sur « Hommage à André Leroi-Gourhan » », Techniques \&

Culture [En ligne], 54-55 | 2010, mis en ligne le 30 janvier 2013, consulté le 29 septembre 2022. URL : http://journals.openedition.org/tc/5044 ; DOI : https://doi.org/10.4000/tc.5044 


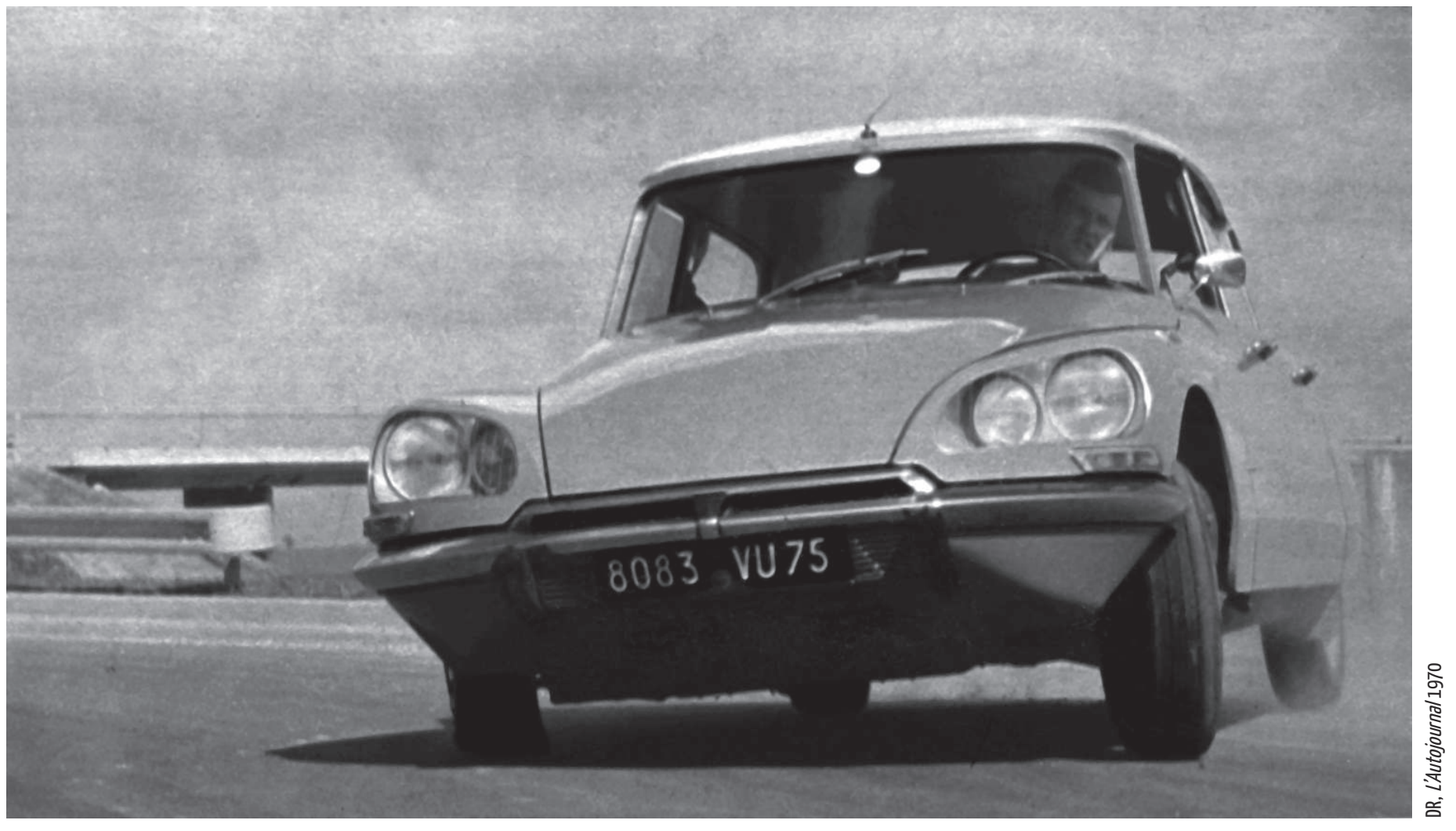




\section{Pierre Lemonnier}

CNRS, Université de Provence, Marseille pierre.lemonnier@univ-provence.fr
Cultures matérielles 1 - I

Techniques E Culture 54-55 volume 1, 2010 : 68-70

\section{Retour sur}

\section{« Hommage à André Leroi-Gourhan »}

Diplômé de l'École Centrale et devenu pilote durant son service militaire (sur « Texan T6 », 1955-1958), Jean-François Quilici-Pacaud fut ingénieur-conseil en brevet d'invention et membre de plusieurs bureaux d'études automobiles, en particulier à la direction de Renault où il défendit, avant l'heure, divers petits véhicules urbains (à trois roues, avec récupération d'énergie au freinage, etc.).

Écrivant dans ce style télégraphique qu'il reconnaît lui-même, ce « technicien spécialisé en mécanique » utilisait volontiers des formules quasi elliptiques - « Le premier artéfact opérant fige le genre », par exemple-, que le lecteur ou l'auditeur était invité à discuter, voire expliciter avec lui, comme je le fis à propos de son texte sur Spratt, un pionnier de l'aviation (Quilici-Pacaud 1993a). Celui qui suit est dans cette veine: brillant, foisonnant d'idées et de sous-entendus, trop concis.

Son point de vue est celui d'un conseil en brevets, d'un mécanicien féru d'histoire de l'automobile et de l'aviation (Quilici-Pacaud 2000) et d'un inventeur qui déposa une dizaine de brevets (vélo anti pirouette, palmes de nageur de fond, ailes de planeurs et d'ULM, tire-bouchon). C'est aussi celui d'un lecteur de H. A. Simon ayant un regard de «systémicien » habitué à démêler les situations complexes (Quilici-Pacaud 1989). Cet hommage à Leroi-Gourhan est donc celui d'un praticien habitué à préciser les différences et ressemblances entre deux objets, instruments, machines ou processus technique, tant pour établir l'originalité des brevets proposés que pour créer des objets nouveaux.

Au premier rang de ces « moyens révélateurs » se trouve une méthode d'observation, de description et d'analyse, de « démontage » (Quilici-Pacaud 1987), portant sur des éléments concrets des objets techniques. En l'occurrence, un téléphone (classique) (fig. 2), qu'il s'attache à décrire et comprendre en termes d'« organicité » (« quoi? », quels éléments? repérés par quels noms), de «fonctionnalité » (« pour quoi faire » ces éléments, et quels 
verbes pour le dire?) et de « relationnalité » («avec quoi » ces éléments sont-ils reliés, et quels graphes indiquent ces liens?). Il insiste ensuite sur le recours à des analogies et à des exercices de pensée aussi simples que l'usage de couple de mots "symétriques » (plein/creux, dur/mou, pousser/tirer, etc.) pour saisir la spécificité de ce que l'on observe.

Une fois exposé son attitude de recherche, Jean-François Quilici-Pacaud se propose, pour l'illustrer, de « reprendre en les affinant certaines taxinomies mises en évidence par Leroi-Gourhan ». Intrigué à l'idée qu'une percussion puisse être posée (une contradiction pour un mécanicien, car qui dit percussion dit vitesse de l'outil), il expose d'abord en mécanicien la façon dont agit une lame et propose de distinguer " coupe par appui », « coupe par percussion » et « percussion avec percuteur », combinant appui et percussion.

Dans ce qui constitue des variations sur le thème de la percussion, Jean-François QuiliciPacaud envisage diverses entrées, critères, facteurs susceptibles d'être pris en compte, à la fois pour classer et comparer divers objets associés à cette forme d'action sur la matière -ici des outils et des armes - et pour retracer leur évolution. Il insiste sur le besoin de distinguer les fonctions complémentaires demandées par un même type d'actions, comme « viser juste » et « taper fort », dans le cas des percussions. Il montre également comment les « dipôles couples de mots antonymes » aident à penser et mettre en ordre des actions de ce type: « outils/armes », «tirer/pousser », « garde [au sens de distance de sécurité] / portée (d'une arme)», etc.

Peu ou pas utilisé (j’avoue mon ignorance), ce texte précurseur reste d'actualité, car il ne fait aucun doute que ce sont très précisément des propositions de ce type qui seront mises en œuvre le jour où sera, enfin, prise au sérieux l'idée d'une étude comparée des modes d'application des moyens élémentaires d'action sur la matière.

Emporté en trois mois par un cancer, Jean-François est mort le 12 mars 2010, à l'âge de 78 ans. Deux jours plus tôt, lors de ce que nous savions être une dernière rencontre, il m'avait montré son dernier achat, un livre en anglais retraçant la vie d'André Lefebvre, le « père » de la Traction-avant, de la suspension de la « $2 \mathrm{CV}$ » et de la DS - cette DS dont nous avions parlé encore une fois, en même temps que d'Airbus, de Papous, d'Anna Arendt, et, me semble-t-il, de yoga et de sauniers vendéens. 